\title{
Discussion on the Measuring Method of the Electric Resistance of Screen Clothes-Shoes
}

\author{
Hongyun Yu, Rui Li, Weijian Pan, Libin Cui, Cheng Ye, Miao Qian and Wenxian Li \\ The Lab of the Safety Testing Technology about the Electrical Equipment of the State Grid, Hangzhou 310015, China
}

\begin{abstract}
By examining the measuring method of screen clothes-shoes' resistance, the paper proposes a reasonable and effective measuring method of screen clothes-shoes' resistance that can ensure the proper implementation of the preventive test of screen clothes-shoes.
\end{abstract}

Keywords-screen clothes; resistance measuring method; discussion

\section{INTRODUCTION}

With the rapid development of economy, increased power demand and continual expansion of power grid, the electricity transmission capacity is increased continually, leading to tenser and tenser electric power line corridors. As a result, there are more and more multi-circuit lines on the same pole. With such lines put into operation, the working load of live maintenance increases significantly. On the premise that live working technology should be adopted if practical, safety tools for live working has been widely used. To make sure that performance of safety tools for live working meets requirements of the standard, an effective measuring method shall be adopted to measure their performance.

Screen clothes for living working is a kind of safety protective equipment widely used to shield strong electric field to protect personal safety of live working persons. In equipotential living working at a voltage of $110 \mathrm{kV}$ and above, maintenance persons need to wear screen clothes to protect them from high electric field [1]. Safety Code of Electric Power Industry by the State Grid stipulates that equipotential operating persons shall wear the whole set of qualified screen clothes (including hats, coats and pants, gloves, socks and shoes. Equipotential operating persons at 750 or $1000 \mathrm{kV}$ shall also wear face shield) outside normal clothes; and all parts shall be connected well [2]. Because the quality of screen clothes is directly related to the personal safety of maintenance persons, proper tests on screen clothes is an effective measure to ensure the personal safety of equipotential live operating persons [3].

\section{TEChNICAL REQUIREMENTS IN GB/T 6568-2008 ON SCREEN CLOTHES}

Screen Clothes for Living Working, GB/T 6568-2008, states that screen clothes shall have good shielding performance, low resistance, proper discharge current capacity, certain fire resistance and good functional performance related to clothes. It also requires all parts of screen clothes shall be electrically connected by two demountable connectors reliably and that the connectors shall not disengage in working process [4].

Preventive Test Regulation of Tools, Equipment and Devices for Live Working, DL/T 976-2005, stipulates that preventive test of screen clothes covers the ready-made garment (including shoes and socks) resistance and shielding efficiency of the whole set of clothes. The Testing period is 6 months. Requirements on the ready-made garments (including shoes and socks) resistance test are as follows: first the resistance between random two farthest ends of coats, pants, gloves, socks and the resistance of shoes shall be measured, and then the resistance of the whole set of screen clothes (completely assemble coats, pants, socks, gloves, socks, hats and shoes well) shall be measured [5].

It can be seen that there are strict requirements on the resistance of screen clothes to guarantee protective performance of screen clothes and exceeding specified value is not allowed.

\section{Test Procedures Of SCREen Clothes-Shoes IN GB/T 6568-2008}

GB/T 6568-2008 stipulates resistance test requirements of screen clothes-shoes [4].

\section{A. Appearance Inspection}

Before testing, first carry out appearance inspection to shoes to ensure that shoes are not damaged; the surfaces of shoes have no severe wear and the branching connecting lines are in good conditions.

\section{B. Test Requirements}

Lay shoes flat on a brass plate electrode with a size of 300 $\mathrm{mm} \times 200 \mathrm{~mm}$, and then put a cylindrical brass electrode with a diameter of $30 \mathrm{~mm}$ and height of $50 \mathrm{~mm}$ with a binding post on the bottom surface in the shoe, and fill steel balls with a diameter of $4 \mathrm{~mm}$ around the electrode. The steel balls shall cover the whole innersole of shoes and the depth of the balls shall be $20 \mathrm{~mm}$ (as shown in FIG. I., measured at the heel). Measure the resistance between two electrodes with an ohmmeter.

For shoes with branching connecting lines, lay shoes flat on a plate electrode. Fill shoes with steel balls with the diameter of $4 \mathrm{~mm}$. The depth of the balls shall be $20 \mathrm{~mm}$. The resistance can be measured between branching connecting lines and the plate electrode. Shoes with the resistance not larger than $500 \Omega$ are qualified. 


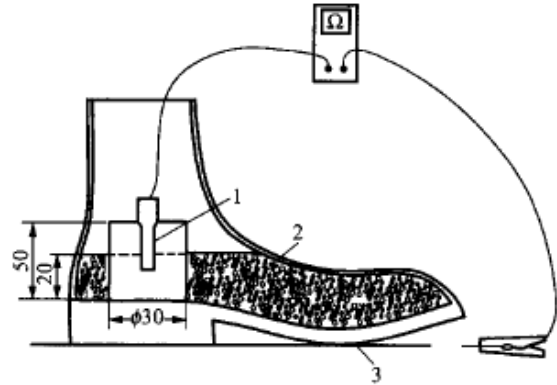

1-Binding post of test electrode; 2-Steel balls; 3-Test electrode FIGURE I. SCHEMATIC DIAGRAM OF MEASUREMENT OF SHOE'S RESISTANCE (IN MM).

\section{Influences Of Practical Measurement Methods}

When actually measuring the resistance of screen clothes-shoes, we find that the resistance is not stable, which brings some difficulties and uncertainty to our judgment on test results. To find a reasonable and effective measuring method, we carry out a series of tests.

\section{A. Measurement Carried out According to GB/T 6568-2008}

As shown in FIG. II, we carry out a measurement according to resistance measuring method of shoes stipulated by $\mathrm{GB} / \mathrm{T}$ $6568-2008$. The depth of steel balls filled in shoes is $22.5 \mathrm{~mm}$. The weight of steel balls is $2 \mathrm{~kg}$. It can be seen from the figure that there is an obvious gap between the sole and the brass plate electrode and the effective contact surface is small. The resistance measured by an ohmmeter needs a very long time to stabilize its value. The resistance decreases slowly with time.

$$
1.4456 \mathrm{k} \Omega \stackrel{\text { after } 5 \mathrm{~min}}{\longrightarrow} 0.9027 \mathrm{k} \Omega \stackrel{\text { after } 5 \mathrm{~min}}{\longrightarrow} 0.8401 \mathrm{k} \Omega
$$

After $10 \mathrm{~min}$, the resistance of shoe $(840.1 \Omega)$ is still larger than the maximum specified value required by $\mathrm{GB} / \mathrm{T}$ $6568-2008(500 \Omega)$.

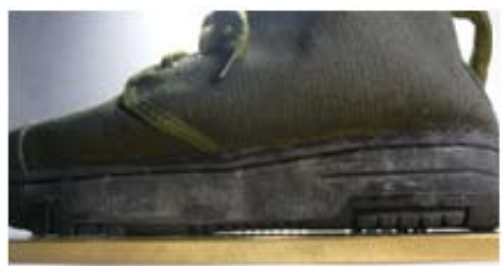

FIGURE II. CONTACT SITUATION BETWEEN SHOE AND BRASS PLATE ELECTRODE (STEEL BALL DEPTH 22.5 MM).

After that, we increase the depth of steel balls in the shoe to $43.2 \mathrm{~mm}$. The weight of steel balls at this time is $3.3 \mathrm{~kg}$. As shown in FIG. III., we can see that the gap between the sole and the brass plate electrode decreases and the effective contact surface increases. However, measured resistance still needs a long time to stabilize its value.

$$
380 \Omega-\frac{\text { after }}{5 \mathrm{~min}} \longrightarrow 242 \Omega-\frac{\text { after }}{5} \stackrel{5 \mathrm{~min}}{\longrightarrow} 197 \Omega
$$

After 10 min, measured resistance $(197 \Omega)$ is smaller than specified value $(500 \Omega)$, and then we remove the shoe from the brass plate electrode for a moment and put the shoe on the brass plate electrode again and test again. The initial value of the resistance of the shoe is $0.708 \mathrm{k} \Omega$, exceeding specified value again. It can be seen from above that poor contact between shoe and the brass plate electrode leads to poor repeatability of test results.

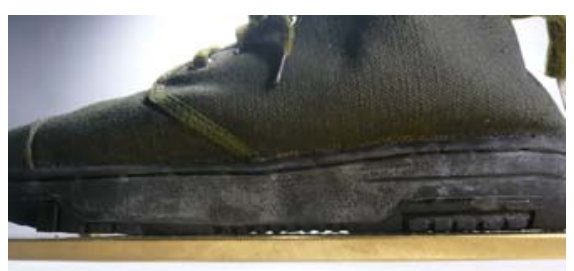

FIGURE III. CONTACT SITUATION BETWEEN SHOE AND BRASS PLATE ELECTRODE (STEEL BALL DEPTH 43.2 MM).

\section{B. Adopt Conductive Cloth}

As shown in FIG. IV, the depth of steel balls in the shoe is $22.5 \mathrm{~mm}$, and the weight of steel balls is $2 \mathrm{~kg}$, and a piece of conductive cloth with the resistance similar to that of brass plate is laid under the sole.

It can be seen from FIG. IV that the contact area of the sole with conductive cloth is much larger than those in FIG. II and FIG. III, and the measured resistance is smaller. The change of the resistance of the shoe is shown as follows:

$$
84.62 \Omega \stackrel{\text { after } 5 \mathrm{~min}}{\longrightarrow} 82.53 \Omega \stackrel{\text { after } 5 \mathrm{~min}}{\longrightarrow} 80.26 \Omega
$$

It can be seen from above that not only resistance of the shoe decreases a lot, and the extent of variation of resistance decreases a lot, too.

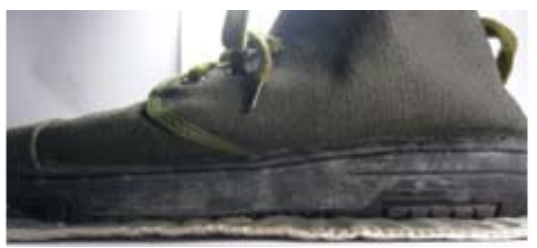

FIGURE IV. CONTACT SITUATION BETWEEN SHOE AND BRASS PLATE ELECTRODE (STEEL BALL DEPTH 22.5 MM).

After that, we increase the depth of steel balls in the shoe to $43.2 \mathrm{~mm}$. The weight of steel balls is $3.3 \mathrm{~kg}$. It can be seen from FIG. V that compared with FIG. IV, there is no obvious change of contact area of the sole with conductive cloth.

$$
68.98 \Omega \stackrel{\text { after } 5 \mathrm{~min}}{\longrightarrow} 69.13 \Omega \stackrel{\text { after } 5 \mathrm{~min}}{\longrightarrow} 69.01 \Omega
$$

Measured initial value of the resistance is $68.98 \Omega$, and after $10 \mathrm{~min}$, the resistance is still about $69 \Omega$. The resistance is relatively stable. Moreover, if the shoe is removed from conductive cloth for a moment, and then placed on the conductive cloth again, the resistance is still about $69 \Omega$, showing good repeatability.

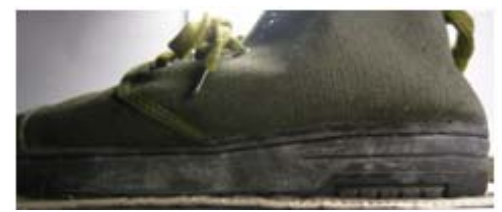

FIGURE V. LAYING A PIECE OF CONDUCTIVE CLOTH UNDER THE SOLE (STEEL BALL DEPTH 43.2 MM). 


\section{Simulation of Real Working Conditions}

During on-site living working, operating persons with screen clothes stand or walk on the angle irons of the iron tower. To simulate the real working conditions, as shown in FIG. VI, a test person with conductive shoes steps on an angle iron to measure the shoe's resistance. The contact area between the sole and the angle iron ( $45 \mathrm{~mm}$ wide) is not very big, but the weight applied is the weight of a human body. The measured resistance of the conductive shoe is $64.26 \Omega$, close to the measured resistance using conductive cloth.

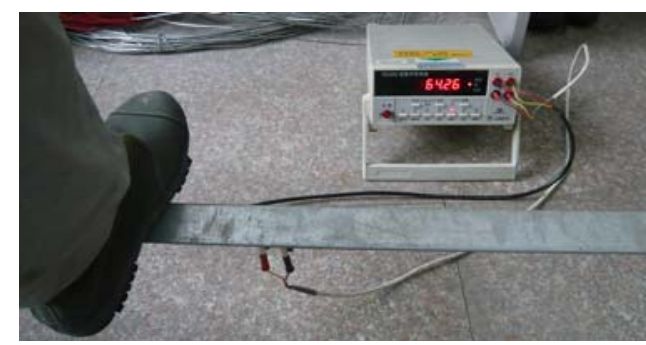

FIGURE VI. A FOOT WITH CONDUCTIVE SHOES STANDS ON AN ANGLE IRON.

\section{DiscusSiOn AND ANALYSIS}

From analysis on measured resistances in above test, we think that:

(1) According to GB/T 6568-2008, the height of steel balls in the shoe shall be $20 \mathrm{~mm}$; because the brass plate of the bottom test electrode is a hard material, the contact area of it with the uneven sole under the weight of $2.3 \mathrm{~kg}$ of steel balls is not consistent, leading to inconsistent resistance measurement values. Besides, variation of the resistance is a little big $(1.4456 \mathrm{k} \Omega \sim 197 \Omega)$, which can easily cause difficulty in judging whether the resistance of the shoe is qualified or not (not larger than $500 \Omega$ ).

(2) If the bottom electrode is replaced by a piece of conductive cloth, because conductive cloth is a soft electrode, as long as shoes are filled with steel balls with the height of $20 \mathrm{~mm}$ and above, the contact area between the sole and the electrode is very ideal, and measured resistance is more stable (84.62 $\Omega \sim 68.98 \Omega$ ), and the repeatability of measured data is better.

(3) In practical use, shoes are under the pressure of body weight of personnel wearing screen clothes. Even if the sole are uneven, the contact between contact surface of the sole and ground objects (such as steel angle) will be closer. When testing person wears conductive shoes to simulate real working conditions, measured resistance is closer to the resistance measured by using conductive cloth.

In conclusion, measuring method in the standard can't measure the real resistance of the screen clothes-shoes.

\section{CONCLUSIOINS}

To ensure the correct implementation of preventive tests of screen clothes-shoes, we think that "when poor contact between the electrode and the sole is found, the bottom electrode can adopt other electrodes (such as conductive cloth with the resistance similar to brass electrode)" should be added to the Standard [6] so as to avoid irrational resistance measurements caused by poor contact of the sole with the brass plate electrode.

Because the quality of electrical safety tools directly affects the personal safety of operating persons, correct and effective preventive test methods should be adopted.

\section{REFERENCES}

[1] Chen Liang et al, Practical Technology FAQ of Personal Protective Equipment for Electrical Working, China Electric Power Press, Beijing, 2009.

[2] State Grid Safety Supervision [2009] 664 Working Safety Regulation for Power Industry of the State Grid (circuit part)

[3] Yu Hong-yun et al. Using and Testing of Electrical Safety Tools and Small Construction Equipment, China Electric Power Press, Beijing, 2007.

[4] GB/T 6568-2008 Screen Clothes for Live Working

[5] DL/T 976-2005, Preventive Test Regulation of Tools, Equipment and Devices for Live Working

[6] Q/GDW-11-42-2010, Preventive Test Regulation of Electrical Safety Tools and Small Construction Equipment 